\title{
Beside P53 and PTEN: Identification of molecular alterations of the RAS/MAPK and PI3K/AKT signaling pathways in high-grade serous ovarian carcinomas to determine potential novel therapeutic targets
}

\author{
SHUHUI CHEN $^{1-4^{*}}$, ELISA CAVAZZA $^{1 *}$, CATHERINE BARLIER $^{1}$, JULIA SALLERON $^{5}$, \\ PIERRE FILHINE-TRESARRIEU ${ }^{1}$, CÉLINE GAVOILLE ${ }^{6}$, JEAN-LOUIS MERLIN ${ }^{1-3}$ and ALEXANDRE HARLÉ Á $^{1-3}$ \\ ${ }^{1}$ Faculty of Pharmacy, Université de Lorraine, 54001 Nancy; ${ }^{2}$ CNRS UMR 7039 CRAN, Université de Lorraine, \\ 54506 Vandoeuvre-les-Nancy; ${ }^{3}$ Department of Biopathology, Institut de Cancérologie de Lorraine, 54519 \\ Vandoeuvre-les-Nancy, France; ${ }^{4}$ Department of Gynecological Oncology, Zhongnan Hospital, Wuhan University, \\ Wuhan, Hubei 430071, P.R. China; Departments of ${ }^{5}$ Data Biostatistics and ${ }^{6}$ Medical Oncology, \\ Institut de Cancérologie de Lorraine, 54519 Vandoeuvre-les-Nancy, France
}

Received April 18, 2016; Accepted July 1, 2016

DOI: $10.3892 / \mathrm{ol} .2016 .5083$

\begin{abstract}
Despite great histological and molecular heterogeneity, the clinical management of high-grade ovarian carcinomas remains unspecialized. As a major subgroup, high-grade serous ovarian carcinomas (HGSOCs) require novel therapies. In addition to utilizing conventional histological prognostic markers and performing oncogenetic investigations, the molecular diagnostic method of next generation sequencing (NGS) was performed to identify 'druggable' targets that could provide access to innovative therapy. The present study was performed in 45 HGSOC patients (mean age, 59.1 years; range, 25-87 years) with histologically proven HGSOC. Breast cancer $1 / 2(B R C A 1 / 2)$ germline mutations were screened in 17 patients with a familial or personal history of cancer, which was justified by oncogenetic investigations. Tumor protein 53 (P53) and phosphatase and tensin homolog (PTEN) expression were assessed in formalin-fixed paraffin-embedded tissues using immunohistochemistry. Somatic mutations of Kirsten rat sarcoma viral oncogene homolog, neuroblastoma RAS viral oncogene homolog (NRAS), B-Raf proto-oncogene, serine/threonine kinase, phosphatidylinositol-4,5-bisphosphate 3-kinase catalytic subunit $\alpha$ (PIK3CA) and MET
\end{abstract}

Correspondence to: Dr Alexandre Harlé, Department of Biopathology, Institut de Cancérologie de Lorraine, 6 Avenue de Bourgogne - CS 30519, 54519 Vandoeuvre-les-Nancy, France

E-mail: a.harle@nancy.unicancer.fr

"Contributed equally

Key words: high-grade serous ovarian carcinoma, signaling pathway, high resolution melting-polymerase chain reaction, immunohistochemistry, targeted therapy, next generation sequencing proto-oncogene, receptor tyrosine kinase $(M E T)$ were screened using NGS on DNA extracts from frozen tumor specimens obtained at diagnosis. With a median follow-up of 38 months (range, 6-93 months), 20 patients are alive, 10 patients are disease-free and 14 patients progressed within 6 months following platinum-based therapy. P53 overexpression was detected in $67 \%$ of patients and PTEN loss was detected in $38 \%$ of the patients. The overexpression of mutant P53 was found to be associated with a longer progression-free and overall survival. In total, 2 NRAS (exon 3), 3 PIK3CA (exon 5 and 10) and 5 MET mutations (exons 14 and 18) were detected. In HGSOCs, in addition to P53 and PTEN alterations, somatic genetic abnormalities can be detected using NGS and provide molecular rationale for targeted therapies, potentially offering novel therapeutic opportunities to patients.

\section{Introduction}

Ovarian carcinoma is the seventh most common cancer in women, worldwide, and the leading cause of mortality from gynecological malignancies (1). Despite the development of surgical techniques and the emergence of novel chemotherapy agents, the 5-year overall survival rate remains poor at $\sim 30 \%$ (2). High-grade serous ovarian carcinoma (HGSOC) is a dominant subgroup of ovarian carcinomas with rapid evolution, late diagnosis and an extremely poor prognosis; these factors justify the requirement for novel therapeutic strategies (3). Numerous genetic alteration events are involved in the molecular mechanisms that underlie cancer development, progression and metastasis. Understanding and elucidating these genetic aberrations in HGSOCs could provide innovative therapeutic options with novel targeted agents.

Tumor protein 53 (P53) alterations are frequently detected in HGSOCs and are associated with high tumor cell proliferation (3). With the exception of its potential as a prognostic marker, P53 alterations could serve as a theranostic 
biomarker in HGSOC. For example, one study reported the destabilization and degradation of mutant P53 by the histone deacetylase (HDAC) 6 inhibitor, vorinostat (4), leading to antitumor activity. In addition, tumor angiogenesis could be inhibited through the downregulation of vascular endothelial growth factor (VEGF), induced by HDAC-mediated hypoxia inducible factor inhibition (5). Therefore, synergistic antitumor activity has been reported with combined inhibition of VEGF and HDAC. HDAC may be induced by pazopanib and vorinostat, which demonstrates better antitumor activity with a significantly longer progression-free survival (PFS) and overall survival (OS) in patients bearing mutant P53 solid tumors, including ovarian cancers, compared with in P53 wildtype tumors (6). Stratifying HGSOC patients on P53 alteration status has, therefore, been proposed as a molecular rationale for the addition of vorinostat to anti-VEGF maintenance therapy, and may maximize the clinical benefits that limit the significant toxicities associated with the use of cytotoxic chemotherapy (7).

RAS/mitogen-activated protein kinase (MAPK) and phosphatidylinositol-4,5-bisphosphate 3-kinase (PI3K)/protein kinase B (AKT) and are two major intracellular signaling transduction pathways that can be activated due to: A loss of phosphatase and tensin homolog (PTEN) function; genetic mutations in phosphatidylinositol-4,5-bisphosphate 3-kinase catalytic subunit $\alpha(P I K 3 C A)$, Kirsten rat sarcoma viral oncogene homolog $(K R A S)$, neuroblastoma RAS viral oncogene homolog $(N R A S)$ or B-Raf proto-oncogene, serine/threonine kinase $(B R A F)(8)$; or the activation of mutations in MET proto-oncogene, receptor tyrosine kinase $(M E T)$ receptors (9) that are involved in the carcinogenesis of HGSOC. These genetic abnormalities are associated with a decreased responsiveness to conventional chemotherapy and a poor prognosis (10-12).

The PI3K/AKT pathway is activated in $\sim 70 \%$ of ovarian carcinomas, and activation of this pathway is associated with increased invasive and migratory capacities of tumor cells and resistance to cytotoxic chemotherapy (13).

PTEN is a major negative regulator of the PI3K signaling pathway and PTEN loss has been reported as a common driver event and prognostic classifier in HGSOC (14). One previous study showed that immunohistochemistry (IHC) is preferable for identifying a loss of PTEN function (15). However, the association between loss of PTEN and patient outcome remains controversial $(14,16)$.

Although $R A S$ mutations have been considered the major molecular feature of low-grade ovarian cancer, NRAS, a member of the $R A S$ family, was found to be an oncogenic driver in HGSOC, which indicates a degree of overlap across the molecular profiles of low- and high-grade ovarian carcinomas (17).

The pathological activation of MET through MET gene mutation is well characterized as a driver in oncogenesis (9) and has been reported to promote tumor proliferation, invasive growth and angiogenesis, which are widely observed in $\operatorname{HGSOC}(8,18)$. In addition, MET activation can promote angiogenesis by activating common signaling pathways such as PI3K/AKT and RAS/MAPK, and the hypoxic environment induced by anti-angiogenic agents has been shown to potentially promote the MET-dependent spreading of cancer cells (19). This finding suggests that the selective targeting of one pathway may induce the compensatory upregulation of another. This may explain that in clinical trials evaluating bevacizumab in ovarian carcinoma, no significant increase of overall survival was observed $(20,21)$, and that the dual inhibition of MET/vascular endothelial growth factor receptor 2 in MET-mutated papillary renal carcinoma (22) demonstrated clinical benefit, as observed in ovarian cancer models (23).

In the present study, in addition to the analysis of oncogenic alterations of P53 and PTEN expression, KRAS, NRAS, BRAF, PIK3CA and MET mutations were screened as putative sources of RAS/MAPK and PI3K/AKT signaling pathways activators. The association of these alterations with the clinical outcome of patients with HGSOC was then evaluated.

\section{Patients and methods}

Patients. Patients treated between January 2007 and December 2012 in Cancer Institute of Lorraine (Vandoeuvre-les-Nancy, France) with a proven diagnosis of HGSOC were selected. In all cases, the final diagnosis was established according to the International Federation of Gynecology and Obstetrics (FIGO) (24) and World Health Organization $(25,26)$ criteria. All women received cytoreductive surgery and a platinum-based chemotherapy and were followed-up in the same institution. Tumor samples were obtained prior to chemotherapy. The present study was approved by the Scientific Committee of the Cancer Institute of Lorraine and all the patients provided formal consent for the study.

Tumor samples. Formalin-fixed paraffin-embedded (FFPE) specimens were used for IHC. Hematoxylin-eosin (H\&E) staining was performed on $5-\mu \mathrm{m}$ sections and the tissue was validated by a senior pathologist (Dr C. Barlier, Cancer Institute of Lorraine). Only specimens with $>20 \%$ tumor cells were used in the study.

Frozen tumor fragments were used for mutation analysis. Cryosections $(5-\mu \mathrm{m})$ were immediately fixed in alcohol, formalin and acetic acid, prior to being H\&E-stained and validated by a senior pathologist to ensure the tumor cell content. Unfixed frozen macrodissected regions with $>20 \%$ tumor cells were then used for DNA extraction using the QIAmp DNA mini kit (Qiagen GmbH, Hilden, Germany). Extracted DNA was then purified and DNA concentration was measured by NanoVue (GE Healthcare Life Sciences, Chalfont, UK) and finally stored at $-80^{\circ} \mathrm{C}$ until processed for polymerase chain reaction (PCR) and next generation sequencing (NGS).

$I H C$. Tissue sections $(5-\mu \mathrm{m})$ were cut from each block and deposited on an IHC-specific slide with a drop of distilled water, prior to being dried on a hot plate and placed overnight in a stove at $56^{\circ} \mathrm{C}$. The sections were deparaffinized and rehydrated using EZ Prep solution (Ventana Medical Systems, Inc., Tucson, AZ, USA) and then restored with Cell Conditioner 1 (Ventana Medical Systems, Inc.) for protein confirmation. Primary mouse anti-human PTEN antibody (dilution, 1:125; catalog no., 9188; clone D4.3; Dako, Glostrup, Denmark) was 
Table I. Clinicopathological characteristics of the patient population.

\begin{tabular}{|c|c|}
\hline Cohort & No. of patients $(\%)$ \\
\hline Total & 45 \\
\hline \multicolumn{2}{|l|}{ Age, years } \\
\hline Mean (SD) & $59.1(12.1)$ \\
\hline Range & $25-87$ \\
\hline \multicolumn{2}{|l|}{ Familial history } \\
\hline Yes & $19(42)$ \\
\hline No & $26(58)$ \\
\hline \multicolumn{2}{|l|}{ Personal history } \\
\hline Yes & $7(16)$ \\
\hline No & $38(84)$ \\
\hline \multicolumn{2}{|l|}{ Oncogenetic counsultation } \\
\hline Yes & $17(38)$ \\
\hline No & $28(62)$ \\
\hline \multicolumn{2}{|l|}{ BRCA mutation $(n=17)$} \\
\hline No mutation & $10(59)$ \\
\hline BRCA 1+ & $5(29)$ \\
\hline BRCA 2+ & $2(12)$ \\
\hline \multicolumn{2}{|l|}{ Tumor stage } \\
\hline I-II & $5(11)$ \\
\hline III-IV & $40(89)$ \\
\hline \multicolumn{2}{|l|}{ Surgery modality } \\
\hline Primary cytoreductive & $36(80)$ \\
\hline Neoadujuvant chemotherapy & $9(20)$ \\
\hline \multicolumn{2}{|l|}{ Surgical outcome } \\
\hline Completed & $21(47)$ \\
\hline Not competed & $24(53)$ \\
\hline \multicolumn{2}{|l|}{ Adjuvant chemotherapy regimen } \\
\hline Single agent platinum & $8(18)$ \\
\hline Platinum/taxane doublet & $31(69)$ \\
\hline Bevacizumab included & $6(13)$ \\
\hline \multicolumn{2}{|c|}{ Response to platinum-based chemotherapy } \\
\hline Sensitive $^{\mathrm{a}}$ & $31(69)$ \\
\hline Resistant $^{\mathrm{b}}$ & $14(31)$ \\
\hline
\end{tabular}

${ }^{a}$ Interval between last course of platinum-based chemotherapy and


platinum-based chemotherapy and disease progression $<6$ months. PFS, progression-free survival; OS, overall survival; SD, standard deviation.

incubated for $1 \mathrm{~h}$ at room temperature and primary mouse anti-human P53 antibody (dilution, 1:50; catalog no., M7001; clone DO-7; Dako) was incubated for $32 \mathrm{~min}$ at $42^{\circ} \mathrm{C}$. The procedure was performed in a BenchMark Ultra ${ }^{\circledR}$ with UltraView Universal DAB Detection kit (Ventana Medical Systems, Inc.) and the sections were lightly counterstained with hematoxylin and bluing reagent (Ventana Medical Systems, Inc.). The IHC results were recorded as follows: Cytoplasmic staining of PTEN was considered as positive; nuclear staining of P53 was considered as positive. The interpretation of staining was blinded from the clinical outcome data.

Mutation analysis by highresolution melting-PCR (HRM-PCR) and NGS. PCR assays were performed to screen somatic mutations in KRAS and NRAS at exons 2, 3 and 4,BRAF at exon 15, and PIK3CA at exons 10 and 21. PCR fragments were stained with Resolight ${ }^{\circledR}$ DNA fluorescent intercalant probe (Roche Diagnostics, Meylan, France) and then amplified using LightCycler $^{\circledR} 480$ High Resolution Melting Master kit (Roche Diagnostics) in a LightCycler ${ }^{\circledR} 480$ thermocycler (Roche Diagnostics) for 35 cycles under the following conditions: $95^{\circ} \mathrm{C}$ for $10 \mathrm{sec} ; 65^{\circ} \mathrm{C}$ for $15 \mathrm{sec}$; and $72^{\circ} \mathrm{C}$ for $30 \mathrm{sec}$.

Appropriate positive and negative controls were included for each of the exons evaluated. The cell lines used as positive controls were: Lovo, Calu6 and ML2 for KRAS, exons 2, 3 and 4); Molt 4, MZ2 and Nalm6 for NRAS, exons 2, 3 and 4; HT29 for BRAF, exon 15; and MCF7 and HCT116 for PIK3CA, exons 10 and 21 . The cell lines used as negative controls were: WIDR for KRAS and NRAS, exons 2, 3 and 4; Lovo for BRAF, exon 15; and MDA-MB231 for PIK3CA, exons 10 and 21.

NGS was performed using ultra-deep biparallel pyrosequencing (GS Junior; Roche Diagnostics) to confirm and identify the somatic alterations detected by HRM-PCR and to further investigate $P I K 3 C A$, exon 5, and MET, exons 14, 16, 17, 18 and 19. Firstly, for the library preparation, sequences of interest were amplified by TAG-PCR and MID-PCR using FastStart High Fidelity PCR System, dNTPack kit (Roche Diagnostics). The procedure was performed using Nexus Mastercycler ${ }^{\circledR}$ (Eppendorf AG, Hamburg, Germany). The PCR products were then controlled by $2 \%$ agarose gel electrophoresis and quantitated using the Quant-iT ${ }^{\mathrm{TM}}$ PicoGreen dsDNA Assay kit (Thermo Fisher Scientific, Inc., Waltham, MA, USA). DNA concentration was finally adjusted to $10^{6}$ DNA molecules $/ \mu 1$. Secondly, the prepared library was amplified by emulsion-PCR using the GS Junior Titanium emPCR kit (Roche Diagnostics) and enriched with the emPCR Bead Recovery Reagents kit (Roche Diagnostics) prior to sequencing with the GS Junior Titanium Sequencing kit (Roche Diagnostics). Data were treated with Amplicon Variant Analyzer software, version 3.0 (454 Life Sciences; Roche Diagnostics, Branford, CT, USA). Sequences were aligned with the NM_002524.4, NM_006218.2 and NM_000245.2 nucleotides for references for NRAS, PIK3CA and $M E T$ sequences, respectively, and variant calling was processed. At x1,000 depth, NGS sensitivity was $1 \%$. A second data analysis using Burrows-Wheeler Aligner 0.7.12 (maximal exact match algorithm; default parameters; distributed under GPLv3) for mapping and sorting and indexing using SAMtools (SAMtools; GitHub, Inc., San Francisco, CA, USA) was performed. VarScan2 (mpileup2snp algorithm; filters-min-coverage 100-minreads 20-min-var-freq 0.01-P-value 0.05) was used for variant calling, as reported previously (27).

Statistics. Quantitative variables were described with the mean, standard deviation and range; qualitative variables by frequency and percentage.

The association between P53 expression, PTEN loss of expression, KRAS, NRAS, PIK3CA, MET mutations and patient age, FIGO stage, chemosensitivity to platinum drugs (defined as lack of tumor progression at 6 months) was analyzed using 
Table II. Association between P53 and PTEN ${ }^{\mathrm{a}}$ protein expression and the clinicopathological features.

\begin{tabular}{|c|c|c|c|c|c|c|}
\hline & $\mathrm{P}^{+} 3^{+}$ & P53- & P-value & $\mathrm{PTEN}^{+}$ & $\mathrm{PTEN}^{-}$ & P-value \\
\hline Expression, n (\%) & $30(67)$ & $15(33)$ & & $24(62)$ & $15(38)$ & \\
\hline Age, n (\%) & & & 0.546 & & & 0.525 \\
\hline$<59$ & $17(57)$ & $7(47)$ & & $14(58)$ & $7(47)$ & \\
\hline$>59$ & $13(43)$ & $8(53)$ & & $10(42)$ & $8(53)$ & \\
\hline FIGO stage, n (\%) & & & 1.000 & & & 1.000 \\
\hline I-II & $3(10)$ & $2(13)$ & & $3(13)$ & $1(7)$ & \\
\hline III-IV & $27(90)$ & $13(87)$ & & $21(87)$ & $14(93)$ & \\
\hline $\begin{array}{l}\text { Response to platinum-based } \\
\text { chemotherapy, n (\%) }\end{array}$ & & & 0.039 & & & 1.000 \\
\hline Sensitive & $24(80)$ & $7(47)$ & & $15(63)$ & $10(67)$ & \\
\hline Resistant & $6(20)$ & $8(53)$ & & $9(37)$ & $5(33)$ & \\
\hline
\end{tabular}

a39 tumors were available for PTEN expression interpretation. P53, tumor protein 53; PTEN, phosphatase and tensin homolog; FIGO, International Federation of Gynecology and Obstetrics.

Chi-squared test or Fisher's exact test. The progression-free survival (PFS) was defined as the time interval between the termination of frontline therapy and the first recurrence either by radiological findings or a rising of CA-125 level by two serial tests $\geq 1$ month apart. Patients alive and free of recurrence were censored at the last follow-up. The overall survival (OS) was defined as the time interval between termination of frontline therapy and fatality (all causes). All causes of fatality were counted as failures. The PFS and OS curves, according to the expression status of P53 and PTEN and the mutational status, were established using logistic regression.

The PFS and OS were described with the Kaplan Meier method. Results are described with cumulative incidence and 95\% confidence interval.

For each outcome, prognostic factors were tested with the Cox proportional hazard model in univariate analysis. Parameters with a $\mathrm{P}$-value of $<0.1$ were introduced in a multivariate Cox proportional hazard model with stepwise selection (with a significance level for entering effects at 0.1 and for removing effects at 0.05).

All statistical analyses were performed using SAS version 9.3 (SAS, Cary, NC, USA). The significance level was set at 0.05 .

\section{Results}

Patient characteristics. In total, 45 patients were included in the present study. The characteristics of the patient population are summarized in Table I. Seven BRCA germline mutations (5 with a $B R C A 1$ mutation, 2 with a $B R C A 2$ mutation) were identified in 17 patients that underwent oncogenetic tests due to a familial and/or personal history of ovarian or breast carcinoma. Successful primary treatment was achieved in all patients through a combination of surgery and 5-8 cycles of platinum-based chemotherapy.

IHC. P53 overexpression was observed in 30/45 tumors (67\%) and PTEN loss of expression was observed in 15/39 tumors
(38\%) (Fig. 1). In addition, 6 cases with negative stromal cell staining for PTEN were considered to be a result of unsuccessful IHC reactions and were excluded from the statistical analysis.

The overexpression of P53 was found to be associated with sensitivity to platinum-based chemotherapy $(\mathrm{P}=0.039)$ (Table II). No other clinicopathological feature was associated with P53 status. No clinicopathological feature was associated with PTEN status.

Mutation analysis. HRM-PCR assay was performed on the tumor DNA extracts from 50 tumors. Out of these 50 samples, 2 cases were found to bear the NRAS, exon 3 , mutation, a no samples possessed KRAS, BRAF or PIK3CA mutations (Table III).

Using NGS, all the mutations found by PCR were confirmed. In addition, 3 mutations of PIK3CA ( 2 in exon 10 and 1 in exon 5) and 5 mutations of MET (4 in exon 14 and 1 in exon 18) were detected (Table III).

The group of patients harboring one of these mutations showed no survival differences compared with the patients without any of these mutations.

Clinical outcome. The median follow-up time was 38 months (range, 6-93 months). Out of the 45 patients, 35 patients showed disease progression and 25 patients succumbed during the follow-up. The 2-year PFS rate was 28\% (range, 16-42\%) and 5-year OS rate was 37\% (range, 21-53\%).

In the univariate analysis, residual disease was significantly identified as predictive factor for a shorter PFS [hazard ratio (HR), 2.134; 95\% confidence interval (CI), 1.080-4.214] and P53 overexpression was found to predict a longer PFS (HR, 0.440; 95\% CI, 0.216-0.894) (Table IVA). There was a trend for a longer PFS among patients belonging to the subgroup with a personal history of breast cancer (HR, 0.319; 95\% CI, 0.097-1.045) or BRCA germline mutations (HR, 0.321; 95\% CI, 0.098-1.054). In the multivariate analysis, P53 overexpression remained significantly associated with a longer PFS (HR, 0.351; 95\% CI, 0.167-0.739) (Table IVA). 

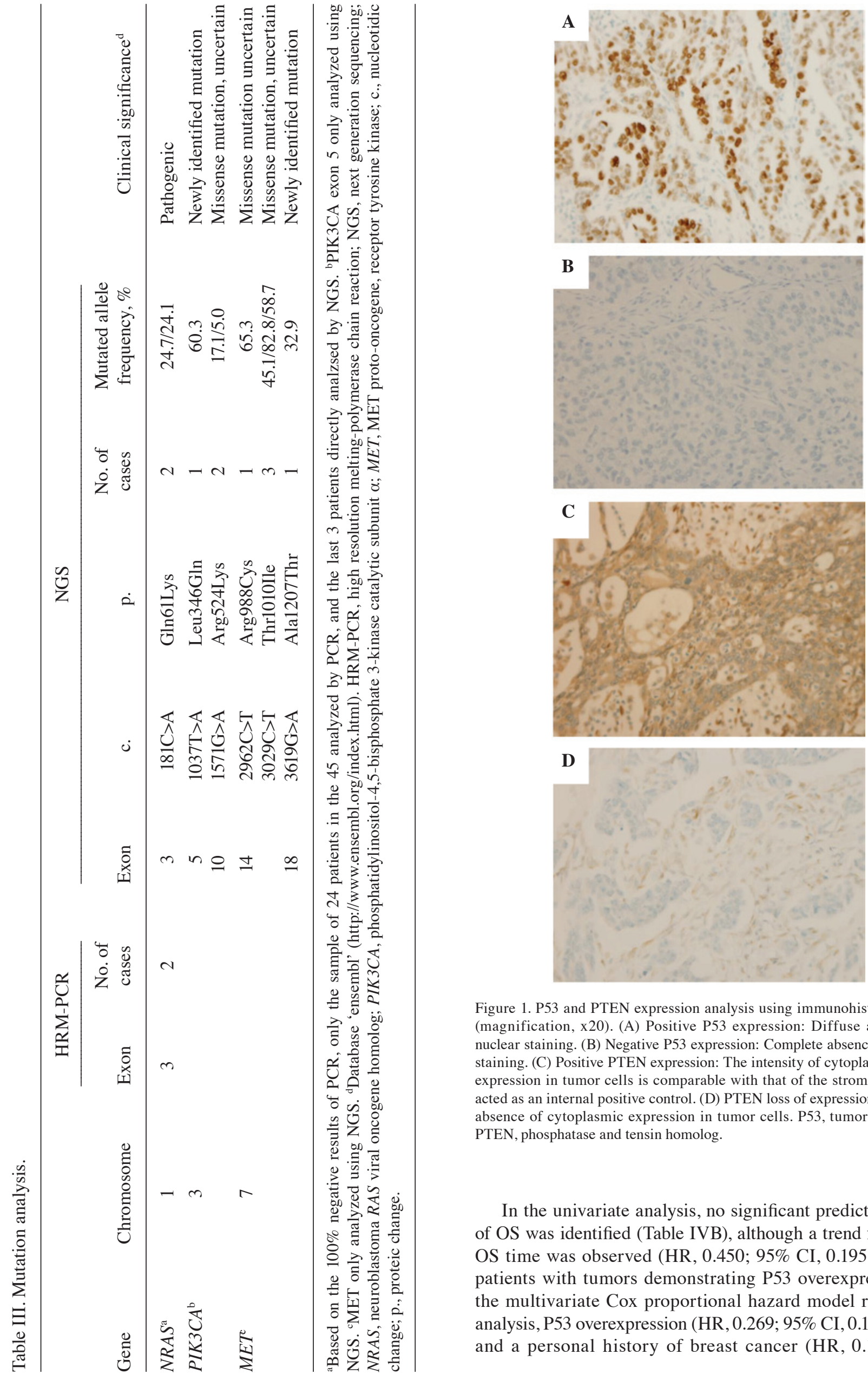

Figure 1. P53 and PTEN expression analysis using immunohistochemistry (magnification, x20). (A) Positive P53 expression: Diffuse and intense nuclear staining. (B) Negative P53 expression: Complete absence of nuclear staining. (C) Positive PTEN expression: The intensity of cytoplasmic PTEN expression in tumor cells is comparable with that of the stromal cells that acted as an internal positive control. (D) PTEN loss of expression: Complete absence of cytoplasmic expression in tumor cells. P53, tumor protein 53; PTEN, phosphatase and tensin homolog.

In the univariate analysis, no significant predictive factor of OS was identified (Table IVB), although a trend for longer OS time was observed (HR, 0.450; 95\% CI, 0.195-1.041) in patients with tumors demonstrating P53 overexpression. In the multivariate Cox proportional hazard model regression analysis, P53 overexpression (HR, 0.269; 95\% CI, 0.102-0.708) and a personal history of breast cancer (HR, 0.168; 95\% 
Table IV. Prognostic factors of (A) progression-free survival and (B) overall survival.

A, Progression-free survival

\begin{tabular}{|c|c|c|c|c|}
\hline \multirow[b]{2}{*}{ Variable } & \multicolumn{2}{|c|}{ Univariate analysis } & \multicolumn{2}{|c|}{ Multivariate analysis } \\
\hline & $\mathrm{HR}$ and $95 \% \mathrm{CI}$ & P-value & $\mathrm{HR}$ and $95 \% \mathrm{CI}$ & P-value \\
\hline Age, years & & 0.1888 & & \\
\hline$<59$ & 1 & & & \\
\hline$>59$ & $1.564(0.803-3.045)$ & & & \\
\hline Family history ${ }^{a}$ & & 0.9632 & & \\
\hline No & 1 & & & \\
\hline Yes & $0.984(0.499-1.942)$ & & & \\
\hline Personal history ${ }^{\mathrm{b}}$ & & 0.0592 & & 0.0286 \\
\hline No & 1 & & 1 & \\
\hline Yes & $0.319(0.097-1.045)$ & & $0.261(0.078-0.869)$ & \\
\hline BRCA mutations ${ }^{\mathrm{c}}$ & & 0.0610 & & \\
\hline No & 1 & & & \\
\hline Yes & $0.321(0.098-1.054)$ & & & \\
\hline Stage & & 0.2443 & & \\
\hline $\mathrm{I}+\mathrm{II}$ & 1 & & & \\
\hline III+IV & $2.030(0.616-6.687)$ & & & \\
\hline Surgery modality & & 0.1014 & & \\
\hline Upfront surgery & 1 & & & \\
\hline Interval surgery & $1.962(0.876-4.395)$ & & & \\
\hline Residual disease & & 0.0029 & & 0.0346 \\
\hline Complete & 1 & & 1 & \\
\hline Non-complete & $2.134(1.080-4.214)$ & & $2.127(1.056-4.286)$ & \\
\hline $\begin{array}{l}\text { Bevacizumab-containing } \\
\text { chemotherapy }\end{array}$ & & 0.8372 & & \\
\hline No & 1 & & & \\
\hline Yes & $1.105(0.426-2.870)$ & & & \\
\hline P53 overexpression & & 0.0233 & & 0.0058 \\
\hline No & 1 & & 1 & \\
\hline Yes & $0.440(0.216-0.894)$ & & $0.351(0.167-0.739)$ & \\
\hline PTEN loss & & 0.7452 & & \\
\hline No & 1 & & & \\
\hline Yes & $0.886(0.426-1.841)$ & & & \\
\hline Mutation status $^{\mathrm{d}}$ & & 0.5259 & & \\
\hline No & 1 & & & \\
\hline Yes & $0.763(0.331-1.758)$ & & & \\
\hline
\end{tabular}

B, Overall survival

Age, years
$<59$
$>59$

Family history ${ }^{\mathrm{a}}$

No

Yes

Personal history ${ }^{\mathrm{a}}$

No

Yes
0.2974

1

$1.524(0.690-3.369)$

1

$0.876(0.393-1.954)$

1

$0.299(0.069-1.284)$
0.1043

0.7463

1

$0.168(0.035-0.809)$ 
Table IV. Continued.

\begin{tabular}{|c|c|c|c|c|}
\hline \multirow[b]{2}{*}{ Variable } & \multicolumn{2}{|c|}{ Univariate analyses } & \multicolumn{2}{|c|}{ Multivariate analysis } \\
\hline & $\mathrm{HR}$ and $95 \% \mathrm{CI}$ & P-value & $\mathrm{HR}$ and $95 \% \mathrm{CI}$ & P-value \\
\hline BRCA mutations $^{\mathrm{c}}$ & & 0.1002 & & \\
\hline No & 1 & & & \\
\hline Yes & $0.186(0.025-1.382)$ & & & \\
\hline Stage & & 0.1804 & & \\
\hline $\mathrm{I}+\mathrm{II}$ & 1 & & & \\
\hline III+IV & $3.933(0.530-29.158)$ & & & \\
\hline Surgery modality & & 0.5155 & & \\
\hline Upfront surgery & 1 & & & \\
\hline Interval surgery & $1.440(0.480-4.318)$ & & & \\
\hline Residual disease & & 0.0961 & & \\
\hline Complete & 1 & & & \\
\hline Non-complete & $1.983(0.885-4.442)$ & & & \\
\hline $\begin{array}{l}\text { Bevacizumab-containing } \\
\text { chemotherapy }\end{array}$ & & 0.6308 & & \\
\hline No & 1 & & & \\
\hline Yes & $0.739(0.216-2.533)$ & & & \\
\hline P53 overexpression & & 0.0619 & & 0.0078 \\
\hline No & 1 & & 1 & \\
\hline Yes & $0.450(0.195-1.041)$ & & $0.269(0.102-0.708)$ & \\
\hline PTEN loss & & 0.9501 & & \\
\hline No & 1 & & & \\
\hline Yes & $1.027(0.442-2.388)$ & & & \\
\hline Mutation status ${ }^{\mathrm{d}}$ & & 0.9655 & & \\
\hline No & 1 & & & \\
\hline Yes & $1.022(0.381-2.741)$ & & & \\
\hline
\end{tabular}

${ }^{\mathrm{a}}$ Family history of ovarian and/or breast cancer. ${ }^{b}$ Personal history of breast cancer. ${ }^{c}$ Mutations in BRCA1/2. ${ }^{\mathrm{d} A n y}$ mutation found in neuroblastoma RAS viral oncogene homolog, phosphatidylinositol-4,5-bisphosphate 3-kinase catalytic subunit $\alpha$ or MET proto-oncogene, receptor tyrosine kinase. HR, hazard ratio; CI, confidence interval; BRCA, breast cancer; P53, tumor protein 53; PTEN, phosphatase and tensin homolog.

CI, 0.035-0.809) were identified as predictive factors of a longer OS (Table IVB).

\section{Discussion}

The median PFS and OS times of the cohort examined in the present study are consistent with previous studies (28).

Considering the IHC of P53, the antibody used in the present study is able to recognize wild-type and non-null mutant P53 (29). When assessed by IHC, non-null mutant P53 often exhibits an intense nuclear staining in a high percentage of tumor cells, whereas wild-type P53 exhibits a moderate nuclear staining in a small percentage of tumor cells. Null-mutant P53 is truncated and unstable, and does not produce nuclear staining (30). In the present study, all P53-positive tumors exhibited diffuse and intense P53 nuclear staining, which may present the non-null mutant P53 group; by contrast, the P53-negative tumors showed a complete absence of nuclear staining, which may present a null-mutant
P53 group (31). This may reflect that P53 alterations occur in almost all HGSOCs, presented as null or non-null mutant P53 (10).

P53 overexpression was observed in 30/45 (67\%) tumors, while the complete absence of P53 expression was observed in $15 / 45$ (33\%) tumors, which is similar to a previous study (32).

The association between the overexpression of P53 and the patient outcome remains controversial, which could be due to the various tumor populations explored, differing methodologies of detection and interpretation of P53 alterations (33). The present study found that P53 overexpression was associated with a longer PFS and longer OS compared with the group with a complete absence of P53 expression, which is consistent with a broad-scale study (32). Although this finding can be explained by the fact that null-mutant P53 is often truncated and has no wild-type P53 function, while non-null P53 retains part of the wild-type P53 function (31), the full the mechanism underlying this difference in outcome is uncertain and requires further investigation. 
Association between loss of PTEN and HGSOC patient outcome remains controversial $(14,16)$. In the present study, PTEN loss was observed in $38 \%$ of tumors, which is similar to a previous study (16). A recent study that evaluated PTEN expression in HGSOC reported an association between loss of PTEN expression and a longer PFS (16). However, other studies suggest that the association of PTEN loss and better prognosis may be partially explained by defected homologous recombination DNA repair function that could be caused by PTEN deficiency (34). This homologous recombination defect could sensitize tumor cells to anticancer drugs, such as platinum or poly ADP ribose polymerase inhibitors (35), similarly to the observations of BRCA-deficient tumors. In the present study, the lack of association of PTEN loss with PFS or OS may be due to the small sample size.

The rate of MET mutations (11\%) observed in the current study is consistent with a previous study (36), and also confirms the juxtamembrane exon 14 mutations, c.2962C>T p.Arg988Cys and c.3029C >T p.Thr1010Ile. These mutations have been reported to induce the constitutive activation of MET in lung cancer cells (37) but were also described as single nucleotide polymorphisms (rs34589476 and rs56391007, respectively) in the ClinVar database (National Institutes of Health, Bethesda, MA, USA). The c.3029C $>$ T p.Thr1010Ile variation has also been associated with ethnic polymorphism in people with Italian heritage, which was the case in one of the patients in the present study, with a mutated allele frequency of $45.0 \%$. In addition, in other studies, these mutations did not enhance any transforming capacity (38), and did not exhibit oncodriver activity but could sensitize tumor cells to MET inhibitors (39). This suggests that these mutational activations of MET could be either an oncogene addiction as an oncodriver in certain cancers or an oncogene expedience as a second event that aggravates the malignant properties of already transformed cells in others (40). In addition, the present study identified a novel mutation in the tyrosine kinase domain (c.3619G >A p.Ala1207Thr on exon 18), for which the association with disease progression and response to therapy remains to be elucidated. The impact of these MET nucleotide variations in the biological or clinical behavior of HGSC requires additional elucidation, as MET inhibition is of great interest for use as a novel therapeutic target, and numerous MET inhibitors are currently under investigation in other types of cancer (40).

Large-scale study showed that the mutation of PIK3CA is usually observed in endometrioid carcinomas (10). In the present study, 2 PIK3CA mutations were detected in 3 patients (7\%) with 1 mutation newly identified (c.1037T >A p.Leu346Gln) and requiring further investigation into its impact on protein function and tumor behavior. This mutation frequency is consistent with another study that performed a small sample size analysis on 2 types of ovarian cancers (41). In the present study, PTEN loss was detected in $1 / 3$ of tumors with $P I K 3 C A$ mutations. This frequency was previously reported in a study whereby $P I K 3 C A$ mutation associated with PTEN loss was sufficient to initiate ovarian tumors in animal models (42). In addition, tumors with PTEN loss were reported to regress when exposed to drugs targeting the PI3K pathway (43). Since $>1 / 3$ of the HGSOC samples presented with a loss of PTEN expression, PTEN loss could be a predictive marker of PI3K pathway activation and the response of
PI3K pathway inhibitors such as NVP-BYL719 (44). Numerous clinical trials (NCT00877773, NCT01219699, NCT01449058, NCT 01501604, NCT01708161, NCT01928459, NCT02439489, NCT02449538 and NCT02449564) of PI3K pathway inhibitors are ongoing in selected patients with tumors harboring PIK3CA mutations or PTEN loss, including HGSOC patients.

Although the RAS/MAPK pathway was considered to be mostly altered in type I ovarian carcinoma (3), the present study has shown that HGSOC could share a similar molecular profile. The NRAS mutation (c.181C>A p.Gln61Lys) identified in 2 patients in the present study had already been reported as an oncogene driver in HGSOC (17). Furthermore, no KRAS or $B R A F$ mutations were found in the present study. This finding confirmed the less frequent dysregulation of the RAS/RAF pathway and the potential interest of NRAS as a biological marker for selecting patients that may benefit from targeted therapy (44). Since the emerging targeted therapy showed antitumor activity in NRAS-mutated cancer (45), the role of NRAS mutations in HGSOC warrants further investigation.

HGSOCs are a group of heterogeneous malignancies that are associated with P53 alteration, PTEN loss and alterations of the PI3K/AKT and RAS/MAPK signaling pathways. Routine therapies have almost reached the efficacy limit and novel therapeutic strategies are urgently required. Mutations in P53 and the loss of PTEN expression are frequent events in HGSOCs. The present study showed that these events are associated with patient outcome; thus, mutations in P53 and the loss of PTEN expression may serve as predictive markers for stratifying patients for appropriate therapy. The observed alterations in the PI3K/AKT and RAS/MAPK pathways elucidate the potential for the clinical application of targeted and personalized therapy, as has been used for other type of cancer.

\section{Acknowledgements}

Dr ShuHui Chen is supported by the China Scholarship Council (grant no. 201208420600; Wuhan, China).

\section{References}

1. Torre LA, Bray F, Siegel RL, Ferlay J,Lortet-Tieulent J and Jemal A: Global cancer statistics, 2012. CA Cancer J Clin 65: 87-108, 2015.

2. Siegel RL, Miller KD and Jemal A: Cancer statistics, 2015. CA Cancer J Clin 65: 5-29, 2015.

3. Kurman RJ and Shih IeM: Pathogenesis of ovarian cancer: Lessons from morphology and molecular biology and their clinical implications. Int J Gynecol Pathol 27: 151-160, 2008.

4. Li D, Marchenko ND and Moll UM: SAHA shows preferential cytotoxicity in mutant $\mathrm{p} 53$ cancer cells by destabilizing mutant p53 through inhibition of the HDAC6-Hsp90 chaperone axis. Cell Death Differ 18: 1904-1913, 2011.

5. Ellis L, Hammers H and Pili R: Targeting tumor angiogenesis with histone deacetylase inhibitors. Cancer Lett 280: 145-153, 2009

6. Fu S, Hou MM, Naing A, Janku F, Hess K, Zinner R, Subbiah V, Hong D, Wheler J, Piha-Paul S, et al: Phase I study of pazopanib and vorinostat: A therapeutic approach for inhibiting mutant p53-mediated angiogenesis and facilitating mutant p53 degradation. Ann Oncol 26: 1012-1028, 2015.

7. Matulonis U, Berlin S, Lee H, Whalen C, Obermayer E, Penson R, Liu J, Campos S, Krasner C and Horowitz N: Phase I study of combination of vorinostat, carboplatin, and gemcitabine in women with recurrent, platinum-sensitive epithelial ovarian, fallopian tube, or peritoneal cancer. Cancer Chemother Pharmacol 76: 417-423, 2015

8. Bast RC, Hennessy B and Mills GB: The biology of ovarian cancer: New opportunities for translation. Nat Rev Cancer 9: 415-428, 2009. 
9. Skead G and Govender D: Gene of the month: MET. J Clin Pathol 68: 405-9, 2015.

10. Cancer Genome Atlas Research Network: Integrated genomic analyses of ovarian carcinoma. Nature 474: 609-615, 2011.

11. Huang J, Zhang L, Greshock J, Colligon TA, Wang Y, Ward R, Katsaros D, Lassus H, Butzow R, Godwin AK, et al: Frequent genetic abnormalities of the PI3K/AKT pathway in primary ovarian cancer predict patient outcome. Genes Chromosomes Cancer 50: 606-618, 2011.

12. Choi KC, Auersperg N and Leung PC: Mitogen-activated protein kinases in normal and (pre)neoplastic ovarian surface epithelium. Reprod Biol Endocrinol 1: 71, 2003.

13. Bai H, Li H, Li W, Gui T, Yang J, Cao D and Shen K: The $\mathrm{PI} 3 \mathrm{~K} / \mathrm{AKT} / \mathrm{mTOR}$ pathway is a potential predictor of distinct invasive and migratory capacities in human ovarian cancer cell lines. Oncotarget 6: 25520-25532, 2015 .

14. Martins FC, Santiago Id, Trinh A, Xian J, Guo A, Sayal K, Jimenez-Linan M, Deen S, Driver K, Mack M, et al: Combined image and genomic analysis of high-grade serous ovarian cancer reveals PTEN loss as a common driver event and prognostic classifier. Genome Biol 15: 526, 2014

15. Djordjevic B, Hennessy BT, Li J, Barkoh BA, Luthra R, Mills GB and Broaddus RR: Clinical assessment of PTEN loss in endometrial carcinoma: Immunohistochemistry outperforms gene sequencing. Mod Pathol 25: 699-708, 2012.

16. Bakkar RM, Xie SS, Urbauer DL, Djordjevic B, Vu K and Broaddus RR: Intact PTEN expression by immunohistochemistry is associated with decreased survival in advanced stage ovarian/primary peritoneal high-grade serous carcinoma. Int J Gynecol Pathol 34: 497-506, 2015.

17. Emmanuel C, Chiew YE, George J, Etemadmoghadam D, Anglesio MS, Sharma R, Russell P, Kennedy C, Fereday S, Hung J, et al: Genomic classification of serous ovarian cancer with adjacent borderline differentiates RAS pathway and TP53-mutant tumors and identifies NRAS as an oncogenic driver. Clin Cancer Res 20: 6618-6630, 2014.

18. Gentile A, Trusolino L and Comoglio PM: The Met tyrosine kinase receptor in development and cancer. Cancer Metastasis Rev 27: 85-94, 2008.

19. Gherardi E, Birchmeier W, Birchmeier C and Vande Woude G Targeting MET in cancer: Rationale and progress. Nat Rev Cancer 12: 89-103, 2012.

20. Oza AM, Cook AD, Pfisterer J, Embleton A, Ledermann JA, Pujade-Lauraine E, Kristensen G, Carey MS, Beale P, Cervantes A, et al: Standard chemotherapy with or without bevacizumab for women with newly diagnosed ovarian cancer (ICON7): Overall survival results of a phase 3 randomised trial. Lancet Oncol 16: 928-936, 2015.

21. Aghajanian C, Goff B, Nycum LR, Wang YV, Husain A and Blank SV: Final overall survival and safety analysis of OCEANS a phase 3 trial of chemotherapy with or without bevacizumab in patients with platinum-sensitive recurrent ovarian cancer. Gynecol Oncol 139: 10-16, 2015.

22. Choueiri TK, Vaishampayan U, Rosenberg JE, Logan TF, Harzstark AL, Bukowski RM, Rini BI, Srinivas S, Stein MN Adams LM, et al: Phase II and biomarker study of the dual MET/VEGFR2 inhibitor foretinib in patients with papillary renal cell carcinoma. J Clin Oncol 31: 181-186, 2013.

23. Zillhardt M, Park SM, Romero IL, Sawada K, Montag A, Krausz T, Yamada SD, Peter ME and Lengyel E: Foretinib (GSK1363089), an orally available multikinase inhibitor of c-Met and VEGFR-2, blocks proliferation, induces anoikis, and impairs ovarian cancer metastasis. Clin Cancer Res 17: 4042-4051, 2011.

24. Zeppernick F and Meinhold-Heerlein I: The new FIGO staging system for ovarian, fallopian tube, and primary peritoneal cancer. Arch Gynecol Obstet 290: 839-842, 2014.

25. Kurman RJ, Carcangiu ML, Herrington CS and Young RH: WHO Classification of Tumours of Female Reproductive Organs. Fourth Edition. World Health Organization, Geneva, 2014.

26. Meinhold-Heerlein I, Fotopoulou C, Harter P, Kurzeder C, Mustea A, Wimberger P, Hauptmann S and Sehouli J: The new WHO classification of ovarian, fallopian tube, and primary peritoneal cancer and its clinical implications. Arch Gynecol Obstet 293: 695-700, 2016

27. Harlé A, Filhine-Tresarrieu P, Husson M, Boidot R, Rouyer M, Dubois C, Leroux A and Merlin JL: Rare RAS mutations in metastatic colorectal cancer detected during routine RAS genotyping using next generation sequencing. Target Oncol 11: 363-370, 2016.

28. Hennessy BT, Coleman RL and Markman M: Ovarian cancer Lancet 374: 1371-1382, 2009.
29. Bonsing BA, Corver WE, Gorsira MC, van Vliet M, Oud PS, Cornelisse CJ and Fleuren GJ: Specificity of seven monoclonal antibodies against p53 evaluated with Western blotting, immunohistochemistry, confocal laser scanning microscopy, and flow cytometry. Cytometry 28: 11-24, 1997.

30. Psyrri A, Kountourakis P, Yu Z, Papadimitriou C, Markakis S, Camp RL, Economopoulos T and Dimopoulos MA: Analysis of p53 protein expression levels on ovarian cancer tissue microarray using automated quantitative analysis elucidates prognostic patient subsets. Ann Oncol 18: 709-715, 2007.

31. Hashimoto T, Tokuchi Y, Hayashi M, Kobayashi Y, Nishida K, Hayashi S, Ishikawa Y, Tsuchiya S, Nakagawa K, Hayashi J and Tsuchiya E: p53 null mutations undetected by immunohistochemical staining predict a poor outcome with early-stage non-small cell lung carcinomas. Cancer Res 59: 5572-5577, 1999.

32. Köbel M, Reuss A, du Bois A, Kommoss S, Kommoss F, Gao D, Kalloger SE, Huntsman DG and Gilks CB: The biological and clinical value of p53 expression in pelvic high-grade serous carcinomas. J Pathol 222: 191-198, 2010.

33. Kmet LM, Cook LS and Magliocco AM: A review of p53 expression and mutation in human benign, low malignant potential, and invasive epithelial ovarian tumors. Cancer 97: 389-404, 2003

34. McEllin B, Camacho CV, Mukherjee B, Hahm B, Tomimatsu N, Bachoo RM and Burma S: PTEN loss compromises homologous recombination repair in astrocytes: Implications for glioblastoma therapy with temozolomide or poly(ADP-ribose) polymerase inhibitors. Cancer Res 70: 5457-5464, 2010.

35. Mendes-Pereira AM, Martin SA, Brough R, McCarthy A, Taylor JR, Kim JS, Waldman T, Lord CJ and Ashworth A: Synthetic lethal targeting of PTEN mutant cells with PARP inhibitors. EMBO Mol Med 1: 315-322, 2009.

36. Tang C, Jardim DLF, Falchook GS, Hess K, Fu S, Wheler JJ, Zinner RG, Naing A, Tsimberidou AM, De Melo Galgiato D, et al: MET nucleotide variations and amplification in advanced ovarian cancer: Characteristics and outcomes with c-Met inhibitors. Oncoscience 1: 5-13, 2013.

37. Ma PC, Kijima T, Maulik G, Fox EA, Sattler M, Griffin JD, Johnson BE and Salgia R: c-MET mutational analysis in small cell lung cancer: Novel juxtamembrane domain mutations regulating cytoskeletal functions. Cancer Res 63: 6272-6281, 2003.

38. Tyner JW, Fletcher LB, Wang EQ, Yang WF, Rutenberg-Schoenberg ML, Beadling C, Mori M, Heinrich MC, Deininger MW, Druker BJ and Loriaux MM: MET receptor sequence variants R970C and T992I lack transforming capacity. Cancer Res 70: 6233-6277, 2010.

39. Arriola E, Cañadas I, Arumí-Uría M, Dómine M, Lopez-Vilariño JA, Arpí O, Salido M, Menéndez S, Grande E, Hirsch FR, et al: MET phosphorylation predicts poor outcome in small cell lung carcinoma and its inhibition blocks HGF-induced effects in MET mutant cell lines. Br J Cancer 105: 814-823, 2011.

40. Comoglio PM, Giordano S and Trusolino L: Drug development of MET inhibitors: Targeting oncogene addiction and expedience. Nat Rev Drug Discov 7: 504-516, 2008.

41. Garrido-Castro AC, Argilés G, Moreno D, RodriguezFreixinos V, Vilaro M, Macarulla T, Cruz Zambrano C, Azaro A, Adamo B, Alsina M, et al: Molecular profiling in gynecologic cancer and matched targeted therapy: A step toward improving personalized medicine. J Clin Oncol 32 (Suppl 5s): 5578, 2014.

42. Kinross KM, Montgomery KG, Kleinschmidt M, Waring P Ivetac I, Tikoo A, Saad M, Hare L, Roh V, Mantamadiotis T, et al: An activating Pik 3 ca mutation coupled with Pten loss is sufficient to initiate ovarian tumorigenesis in mice. J Clin Invest 122: 553-557, 2012.

43. Janku F, Wheler JJ, Westin SN, Moulder SL, Naing A, Tsimberidou AM, Fu S, Falchook GS, Hong DS, Garrido-Laguna I, et al: PI3K/AKT/mTOR inhibitors in patients with breast and gynecologic malignancies harboring PIK3CA mutations. J Clin Oncol 30: 777-782, 2012.

44. Fritsch C, Huang A, Chatenay-Rivauday C, Schnell C, Reddy A, Liu M, Kauffmann A, Guthy D, Erdmann D, De Pover A, et al: Characterization of the novel and specific PI $3 \mathrm{~K} \alpha$ inhibitor NVP-BYL719 and development of the patient stratification strategy for clinical trials. Mol Cancer Ther 13: 1117-1129, 2014.

45. Ascierto PA, Schadendorf D, Berking C, Agarwala SS, van Herpen CM, Queirolo P, Blank CU, Hauschild A, Beck JT, St-Pierre A, et al: MEK162 for patients with advanced melanoma harbouring NRAS or Val600 BRAF mutations: A non-randomised, open-label phase 2 study. Lancet Oncol 14: 249-256, 2013 